\title{
COMUNIDADES VIRTUAIS DE APRENDIZAGEM - BLOG: PREMISSAS SOBRE UMA PESQUISA
}

\section{VIRTUAL LEARNING COMMUNITIES - BLOG: PREMISES ON A SURVEY}

\author{
Andréa Flávia de Brito Gonçalves* \\ Marlene Bíscolo Parrilla ${ }^{* *}$ \\ Márcia Maria Dias Reis Pacheco ${ }^{* * *}$
}

\section{RESUMO}

O objetivo do presente estudo foi analisar os resultados obtidos com a aplicação de um pré-teste, do qual utilizou-se como instrumento de coleta de dados um questionário com questões fechadas. A coleta dos dados foi realizada em uma escola estadual localizada em uma cidade situada na região metropolitana de São Paulo. Para tanto, foram elaboradas algumas questões pertinentes, como: a) analisar as perguntas e sua pertinência em relação aos objetivos específicos da pesquisa; b) observar se as respostas obtidas realmente são eficazes para o desenvolvimento da pesquisa. Os resultados demonstraram que a validação do instrumento proposto foi essencial para verificação de ajustes, como também, para validar o instrumento para a futura coleta de dados no que se refere à uma pesquisa1 em andamento.

Palavras-Chave: Tecnologias; pré-teste; comunidades virtuais de aprendizagem; blog.

\begin{abstract}
based on Gray's proposal (2012) and Malhotra (2010, the aim of this study is to show the importance of the "pre-test" instrument as a way to validate the effectiveness of implementation of data collection questionnaire on scientific research. The pre-test questionnaire was used in a public school in a city in the metropolitan region of São Paulo. Ten (10) subjects participated of the pre-test, a manager, a coordinator and teachers. A quantitative and qualitative approach was adopted for the study, using a questionnaire with twelve (12) closed questions concerning sociodemographic data and information about the use of educational blogs. All data were manually recorded and organized into graphs and charts for content analysis. The results showed that the validation of the instrument was also essential to check settings as to validate the instrument for future data collection in relation to an ongoing research. It was also possible to infer the importance of the theme Blog in the educational context, as the results in the pre-test applied on a small sample demonstrated the relevance of the research to be developed.
\end{abstract}

Keywords: Pre-test; Questionnaire; Educational Blog.

\footnotetext{
"Mestranda do Programa de Pós-graduação em Desenvolvimento Humano: Formação, Políticas e Práticas Sociais pela Universidade de Taubaté. Professora polivalente na Secretaria da Educação do Estado de São Paulo e professora na Secretaria Municipal de Educação de São José dos Campos.

${ }^{*}$ Mestre em Desenvolvimento Humano: Formação, Políticas e Práticas Sociais pela Universidade de Taubaté, UNITAU, Brasil. Professora do Instituto Educacional do Vale do Paraíba, IEVAP, Brasil.

${ }^{* * *}$ Doutora em Educação (Psicologia da Educação) pela Pontifícia Universidade Católica de São Paulo, PUC/SP, Brasil. Docente do Programa de Mestrado Interdisciplinar em Desenvolvimento Humano: Formação, Politicas e Práticas Sociais da Universidade de Taubaté (UNITAU).

${ }^{1}$ Refere-se à uma dissertação de Mestrado intitulada "O Blog no contexto educacional: o uso deste ambiente virtual em escolas públicas".
} 


\section{Introdução}

A ascensão das "Tecnologias da Informação e Comunicação" - TIC's modificaram diferentes setores da sociedade, tornando-se presentes e fundamentais no cotidiano das pessoas.

Diante dessa realidade, houve a necessidade de prepará-las para resolver os problemas voltados à utilização das TIC's em diferentes locais como bancos, escolas e até mesmo no trabalho.

Os recursos atuais da tecnologia, as inovações dos meios digitais, a multimídia, a internet, a telemática, trouxeram perspectivas diferenciadas em ações como ler, escrever, pensar e agir, que acarretou o desenvolvimento de novos conhecimentos voltados principalmente à criatividade, à criticidade, à construção de uma cultura de rede, como também à diversidade cultural e à democratização.

Essa dinâmica induz uma reformulação no modo como se entendia o conhecimento, pois:

$\mathrm{Na}$ atualidade o domínio de apenas a leitura e escrita apresenta-se insuficiente já que só permite acessar uma parte da informação veiculada em nossa sociedade que está acessível em livros. Uma pessoa analfabeta tecnologicamente está à margem da rede comunicativa que oferecem as TIC's. O desafio colocado a cada cidadão é a capacitação tecnológica, ou seja, o desenvolvimento de habilidades, que forneçam condições para viver num ambiente altamente tecnológico que exige um uso crítico e não meramente instrumental das TIC's. Realizar um projeto abrangente e eficaz de inclusão digital é fundamental para transformar a sociedade em que vivemos em um ambiente mais justo e igualitário, e a escola desempenha papel fundamental para esse novo projeto da sociedade, exigindo uma postura inovadora diante da realidade da Sociedade do Conhecimento (OLIVEIRA, 2006, p.11).

Grinspun (2009) também explica esta evidência ressaltando que a sociedade atual vive em crise constante para ajustar-se a esses grandes desafios:

Temos uma sociedade marcada por contradições e desafios da civilização científica tecnológica: altos avanços neste campo capazes de fazerem a vida mais humana, mais longa, com uma cultura, hoje, de lazer, mas que outro lado nos levam, por suas estratégias, a termos uma situação de domínio, destruição e até mesmo de alienação. A moderna civilização convive com esses contrastes, mas também com suas aspirações (GRINSPUN, 2009, p.50).
A escola tem papel fundamental neste contexto de mudança e precisa constituir-se em um local privilegiado de debates, discussões e reflexões que concorra para uma formação que permita a inserção das crianças e jovens em uma sociedade altamente tecnológica.

Kenski (2012) afirma que a presença de uma determinada tecnologia pode induzir profundas mudanças na maneira de organizar o ensino, alterando profundamente a natureza do processo educacional e a comunicação entre os participantes. Ainda, segundo ele, a escolha do recurso tecnológico utilizado está intrinsecamente ligada às questões estruturais e objetivas educacionais instituídas.

Desta forma, acredita-se que a escolha pela pesquisa Ambiente virtual - blog - como recurso tecnológico a ser explorado pelas instituições educativas seja relevante, pois acredita-se que a elaboração de blogs em unidades escolares contribuirá para a discussão dos objetivos da inserção e manutenção desses ambientes no âmbito educacional.

Nesta direção, a investigação através do instrumento de pesquisa - questionário fechado - procura buscar indicadores evidenciados pela opção dos gestores e professores de escolas públicas estaduais pelo ambiente virtual - blog (comunidades virtuais de aprendizagem), no sentido de ampliar os olhares sobre essa ferramenta tecnológica cada vez mais utilizada pelas escolas.

\section{Comunidades de aprendizagem - blog}

A sociedade atual vive em um mundo marcado por intensas mudanças, porém, nenhuma das $\mathrm{TIC}^{\prime} \mathrm{s}$ parece entusiasmar tanto quanto o uso de computadores e a internet. Sorj (2003) enfatiza duas atividades ligadas a esses recursos: a manipulação do conhecimento e a comunicação através da integração entre computadores e internet.

A informática representa a possibilidade de armazenar, organizar e processar uma quantidade enorme de informação em um espaço ínfimo e numa velocidade que praticamente elimina o tempo, revolucionando a capacidade humana - e das máquinas- de trabalhar com informação. As novas tecnologias da comunicação ao permitirem a comunicação instantânea entre computadores, em escala mundial, de voz, texto ou imagem, 
disponibilizam cada vez mais informação a um custo menor (SORJ, 2003, p.36).

A conjuntura das duas tecnologias criou a telemática, sendo o protocolo mais difundido, a internet. A internet seria a ligação entre computadores, uma rede de conexão em tempo real que permite a qualquer pessoa em qualquer lugar do planeta ficar disponível quase que instantaneamente.

A informação obtida através da rede, passa a constituir uma configuração completamente diversa da espacialmente instituída, ultrapassando as barreiras geográficas e criando um novo ambiente a ser explorado, o Ciberespaço.

Faria e Giraffa (2009) concordam que com o advento da internet modificou a forma como a sociedade se comunica e, consequentemente, a forma como se aprende.

As escolas, observando este aspecto, investem cada vez mais em laboratórios de informática e instigam educadores a utilizar mais o recurso "computador" em sua prática. Certamente que, a popularização desse instrumento na escola veio acompanhada de inúmeras inquietações, que são retratadas de forma pontual que, de acordo com Hasse (2000):

[...] a falta de informações mais consistentes e científicas sobre a implementação e utilização do computador dentro da escola tem gerado, na comunidade educativa, questionamentos variados, infundados, opiniões antagônicas e ilusórias, mistificando as reais possibilidades e limitações deste instrumento no processo de ensino aprendizagem. Urge, então, abandonar a firmeza com que nos apegamos a essas ideias falsas e imaginárias. Para tanto é importantíssimo, em um primeiro momento, para a busca de explicações sólidas, ou seja, fruto de pesquisas e reflexões sistemáticas que muito podem contribuir para esclarecer das expectativas fundadas em supostos benefícios, das dúvidas e dos receios em torno do binômio "educação informática" (HASSE, 2000 p.124).

Mesmo sem equacionar esse binômio, muitas escolas resolveram aventurar-se na internet e suas interfaces - comunidades virtuais. Kenski (2003), explica como esses espaços funcionam na prática:

As comunidades virtuais não se diferenciam das comunidades que conhecemos no mundo físico. As pessoas circulam nas comunidades virtuais, transferem para elas seu modo de vida, seu modo sua cultura. Essas comunidades não são réplicas do mundo físico ou reproduções das esferas sociais tradicionais. A própria forma de agregação socialnão imposta, a não ser pelo interesse pessoal - já os diferencia. As possibilidades de superação dos limites de espaço e tempo, as agregações de pessoas sem as costumeiras barreiras e limites que ocorrem na vida social mostram as potencialidades existentes nesses grupos e que permitem realizar atividades que não são possíveis no mundo físico (KENSKI, 2003, p.115).

Os chats, blogs, grupos de discussões, fóruns, entre outros, despertaram em muitos educadores, pesquisadores da área educacional, para um novo olhar. Suas possibilidades, o grau de interesse, o engajamento do corpo docente e a fluidez social de seu uso conduziram para a descoberta de uma funcionalidade diferente da que ela tinha sido criada: a de comunidades interessantes para a exploração na área educacional.

Muitos estudiosos consideraram essas interfaces como comunidades globais de aprendizagem, e mais, como canais de comunicação importante na integração da comunidade escolar que de acordo com Jobim (2006):

A internet não é apenas uma rede onde transita a informação. É um espaço que abrange diversos meios, que ao serem cada vez mais utilizados com multiplicação e proliferação dos chats, grupos de discussão, listas de discussão, fóruns, blogs, trocas instantâneas de mensagens, etc. evidenciam novos padrões de interação social e vem caracterizando-a como uma comunidade virtual.

Novas formas de ferramentas como blogs e wikis, ao serem incorporadas na educação, permitem explorar novas formas de interação didática, com a eliminação de limites de espaço e tempo, e consequentemente promovem a criação de verdadeiras comunidades globais de aprendizagem (JOBIM, 2006 p.89).

Mas, como este cenário está realmente institucionalizado? Quais objetivos educacionais estão sendo contemplados?

Adell (2010) provoca reflexões sobre o uso destes ambientes, como da internet de maneira geral no âmbito educacional quando atesta que a internet e suas interfaces "comunidades virtuais" podem ser fontes ricas de aprendizagem. Porém, alerta que seu uso equivocado pode tornar-se mais um 
desdobramento do ensino unilateral em que alunos utilizam essas ferramentas apenas como meros receptores e não protagonistas do processo.

Desta forma, o ensino poderia estar se consolidando em práticas metodológicas equivocadas, que minimizam o processo de ensino e aprendizagem sem que os próprios protagonistas percebam.

Jobim (2006) afirma que não basta ter uma comunidade virtual de aprendizagem, é preciso que os integrantes desta contribuam efetivamente e substancialmente para o seu desenvolvimento. Behrens (2006) propõe que a aprendizagem se dê de forma colaborativa, enfatizando que este tipo de ação educativa busca no prazer em descobrir, investigar, construir, reconstruir e compreender que o aprender é um fazer inesgotável.

Estas hipóteses parecem ser possíveis graças ao fascínio causado pelas máquinas, cegando aqueles que delas usufruem. Por esse motivo, é necessário ter alguns cuidados na implementação de recursos tecnológicos nas escolas. Belloni (2005) reforça esta ideia ao afirmar que:

[...] é fundamental reconhecer a importância das TIC's e a urgência de criar conhecimentos e mecanismos que possibilitem sua integração à educação, é preciso evitar o deslumbramento que tende a levar ao uso mais ou menos indiscriminado da tecnologia por si e em si, ou seja, mais por suas virtualidades técnicas do que por virtualidades pedagógicas (BELLONI, 2005, p.24).

Buscando a virtualidade pedagógica, os $b \log s$ surgem no âmbito educacional como um ambiente de grandes possibilidades. Relativamente fáceis de criar, oferecem, em sua interface, formas colaborativas de aprendizagem, tendo como principal característica a regularidade de postagem de informações.

Pensando no âmbito educacional, esta ferramenta desdobra-se e ganha um novo significado, o de edublog, por ser uma ferramenta, de acordo com Bherens (2006), de docência, aprendizagem e investigação.

Oliveira (2006) expõe que os blogs tem tido uma grande aceitação do meio acadêmico. Valente et al. (2011) corroboram com essa ideia, acrescentando que:

Atualmente, há um uso crescente dos blogs por professores, tanto na educação a distância como presencial. Eles possibilitam a atualização constante de informações, pelo professor e pelos alunos, favorecendo a construção de projetos, pesquisas individuais e em grupos, bem como a divulgação de trabalhos (VALENTE et al., 2011, p.119).

As instituições escolares podem usar os blogs como páginas de conteúdos, divulgação de trabalhos, projetos, avisos, artigos, sugestões de links de leituras de conteúdos abordados na escola entre outros. Possa, ainda, aproveitar esse espaço para proporcionar debates, desenvolver fóruns on-line, enfim, este ambiente pode ser desfrutado de maneira interativa por toda a comunidade educativa.

\section{Método}

Para o desenvolvimento da pesquisa foi realizado um pré-teste do questionário a ser utilizado na pesquisa, visando avaliar sua pertinência, coerência, objetividade e clareza. Gray (2012) alega ser vital este processo inicial já que uma testagem bem feita pode reduzir falhas na elaboração das perguntas e proporcionar mais segurança aos respondentes, evitando desistência para realização da pesquisa.

O questionário foi aplicado a uma pequena amostra de 10 sujeitos (gestores e professores) que teve por finalidade:

a) Traçar o perfil sócio-demográfico dos possíveis sujeitos envolvidos na construção e elaboração dos blogs das escolas estaduais;

b) Compreender a relação dos sujeitos com o ambiente em que o objeto de estudo - blog escolar se encontra alojado;

c) Detectar os possíveis colaboradores na manutenção do blog escolar e suas ações na efetivação desse ambiente no âmbito educacional.

Para que estes objetivos iniciais fossem considerados, realizou-se uma análise do instrumento, observando:

- Dificuldades de entendimento;

- Ambiguidade de questões;

- Existência de perguntas desnecessárias;

- Organização das perguntas.

Lopes (2006) afirma que há três elementos essenciais a serem verificados: fidedignidade, validade e operatividade. Segundo esse autor, o primeiro deles refere-se à unidade de respostas dos respondentes 
independentemente da pessoa em que se aplica. O segundo, à importância de se obter dados suficientes nas respostas que considerem todos os objetivos iniciais da pesquisa. Por último, à clareza no vocabulário tornando as perguntas claras a todos os entrevistados.

Procurando seguir esta perspectiva, deu-se início a aplicação do pré-teste, relatando os pré-resultados e as possibilidades de melhoria do instrumento de pesquisa.

\section{Premissas para o pré-teste}

Segundo Gray (2012), o questionário é uma importante ferramenta de coleta de dados, pois pode ser usado em muitas das metodologias de pesquisa. No entanto, é fundamental que seja cuidadosamente elaborado e aplicado. Um teste piloto sobre sua função é imprescindível para validá-lo como instrumento para pesquisas posteriores.

Objetivando atender estes princípios, o instrumento "questionário" foi planejado pelas pesquisadoras junto à orientadora tendo por base os objetivos específicos da pesquisa real: a) identificar quais estratégias definem a elaboração e os conteúdos postados nos blogs; b) analisar conteúdos expressos nos $b \log s$, identificando os aportes teóricos que lhes dão sustentação e analisando as finalidades educativas; c) compreender os significados e implicações dos blogs na dinâmica educacional.

A estrutura inicial deste instrumento contemplou duas partes: a primeira constituiu-se da identificação do local (diretoria de ensino, unidade escolar, endereço) e do perfil sócio- demográfico dos respondentes (nome, data de nascimento, formação, cursos que consideram relevantes, jornada de trabalho, atuação, tempo de atuação na área educacional, tempo de atuação na unidade escolar em que trabalham atualmente).

A segunda parte reportou-se às perguntas que demonstrassem a familiaridade dos respondentes quanto à prática das $\mathrm{TIC}^{\prime}$ s e do blog especificamente, seja em seu cotidiano, no trabalho ou em atividades pessoais.

Após concluir essa fase, foi realizada uma triagem para a escolha de uma escola em que pudesse fazer o pré-teste do instrumento, seguindo as orientações de Malhotra (2010) "Os entrevistados no pré-teste devem ser semelhantes aos entrevistados na pesquisa real em termos de características fundamentais, familiaridade com o assunto, atitudes e comportamento de interesses" (MALHOTRA, p. 238).

Dessa forma, uma escola foi eleita, por apresentar características equivalentes às instituições que serão estudadas posteriormente. Em visita prévia à escola, as pesquisadoras requereram autorização do gestor responsável, explicando como ocorreria o processo de aplicação questionário para o pré-teste e os motivos pelos quais a escola havia sido selecionada.

Conforme agendamento, as pesquisadoras dirigiram-se a unidade escolar de posse dos seguintes documentos:

- Termo de Autorização da Instituição Escolar (que esboçava, em seu conteúdo, a autorização expressa da unidade escolar para aplicação do pré-teste);

- Termo de Consentimento Livre e Esclarecido para pré-teste (convite para participação voluntária na pesquisa, garantindo-se aos participantes o sigilo e o anonimato e o direito de se retirar o consentimento em qualquer tempo).

Todos os sujeitos, nesse momento, foram notificados formalmente, como também foram esclarecidas dúvidas sobre objetivos da pesquisa e do teste piloto, os procedimentos e os benefícios decorrentes da participação dos respondentes. Além disso, receberam orientações sobre o sigilo e as possíveis formas de divulgação dos dados tais como: publicação em periódicos e/ou apresentação de eventos científicos.

Após essas premissas fundamentais, o préteste do "questionário" foi aplicado efetivamente.

\section{Resultados}

Como esboçado acima, o questionário apresentou duas categorias. A primeira refere-se às perguntas relacionadas à classificação dos sujeitos, traçando o perfil sóciodemográfico dessa população. O segundo está diretamente ligado ao perfil do sujeito quanto ao uso das TIC's em seu cotidiano, no trabalho e sua afinidade com o blog das instituições escolares em que atuam.

Seguindo esta organização, inicia-se a análise dos dados encontrados na primeira categoria. 
Figura 1-Faixa etária dos sujeitos

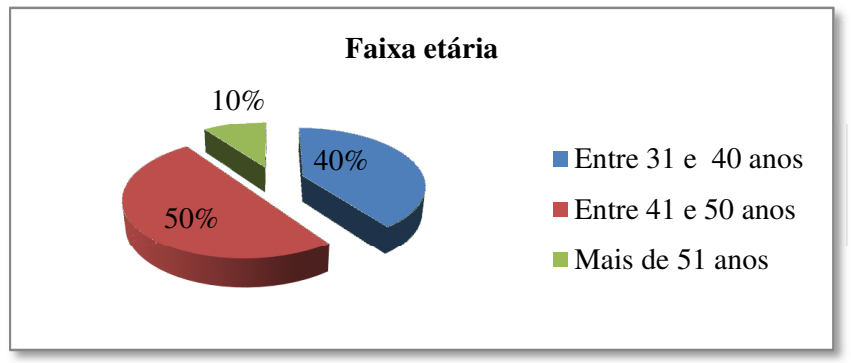

Fonte: Elaborado pelas autoras

Ainda de acordo com esse autor, na instituição escolar, encontramos diferentes gerações professores de diferentes faixas etárias e ainda os jovens alunos, e este encontro criar conflitos geracionais entre os grupos e descompassos de práticas metodológicas. Sendo assim, faz-se necessário aprofundar estudos sobre este ponto específico (UNGLAUB, 2012).

Ao propor que os respondentes citem os cursos de licenciatura realizados, foram encontrados os seguintes dados:

Figura 2-Número de cursos de licenciatura por sujeito

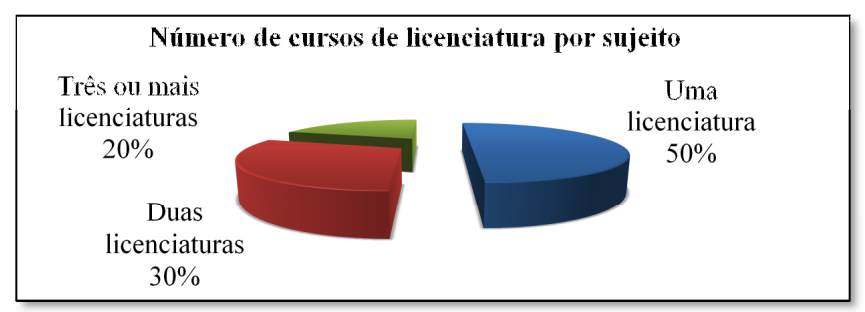

Fonte: Elaborado pelas autoras

Informalmente muitos relataram que a segunda licenciatura, assim como cursos de capacitação, foram frutos de necessidades encontradas no trabalho desenvolvido e que eles próprios desembolsaram recursos para ter acesso a novos conhecimentos necessários à sua prática.

Foram diversos cursos extras considerados importantes pelos respondentes. A tabela 1 demonstra os dados encontrados sobre este item.
Tabela 1 - Cursos considerados pelos sujeitos como importantes para sua formação e atuação profissional

\begin{tabular}{l|c}
\hline $\begin{array}{l}\text { Cursos que considerem relevantes respostas } \\
\text { encontradas }\end{array}$ & No de sujeitos \\
\hline Direcionados a Área Pedagógica & 1 \\
\hline Pedagogia & 1 \\
\hline Pós-Graduação em Gestão Escolar & 1 \\
\hline Teatro & 2 \\
\hline Informática & 2 \\
\hline Inglês & 1 \\
\hline Cursos oferecidos pela FGV gratuitamente & 1 \\
\hline $\begin{array}{l}\text { Pós- graduação: docência para o ensino } \\
\text { superior }\end{array}$ & 1 \\
\hline Dança & 1 \\
\hline $\begin{array}{l}\text { Todos voltados à área da educação e área } \\
\text { administrativa }\end{array}$ & 2 \\
\hline Não respondeu & \\
\hline
\end{tabular}

Fonte: Elaborado pelas autoras

Nesta pequena amostra, nota-se que há interesse em se estar em constante aprendizagem, porém percebe-se que os investimentos para que isso ocorra não parte da instituição em que atuam, mas de seus recursos próprios. Este ponto leva a discussões sobre a efetiva participação da Secretaria da Educação do Estado de São Paulo em cursos que realmente sejam importantes para a melhoria da prática docente.

Dos cursos evidenciados pelos sujeitos, 2 (dois) em especial chamaram a atenção, por estarem diretamente ligados ao objeto de estudo abordado na pesquisa blog: informática e inglês. Como o blog é uma interface alojada no Ciberespaço, o conhecimento em informática e inglês é essencial para o aprofundamento de suas possibilidades.

$\mathrm{Na}$ informática, o domínio básico é imprescindível para que os sujeitos consigam explorar a máquina (computador) que nada mais é do que a via de acesso às interfaces do Ciberespaço. Ter domínio da língua inglesa pode auxiliar a compreender e aprimorar o uso deste ambiente, já que muitos postulados e ferramentas utilizadas dentro dos blogs (como os HTML) ainda não foram traduzidos para a Língua Portuguesa.

$\mathrm{Na}$ segunda parte do questionário analisou o envolvimento dos sujeitos:

- Verificar se os sujeitos têm em seu cotidiano acesso à internet e conhecem algumas de suas ferramentas; 
- Analisar qual é o papel e participação desses sujeitos na elaboração do blog da escola.

A primeira pergunta refere-se a verificar os locais onde o sujeito tem acesso ao computador. Esta primeira pergunta não dava aos sujeitos a liberdade de colocar respostas múltiplas, pois o objetivo era averiguar em qual local este sujeito costuma usar mais o computador. Mas, mesmo sendo orientados, $70 \%$ deles optaram por colocar respostas múltiplas. Isto demonstra que esta pergunta necessitava de uma observação para que os respondentes não tivessem dúvidas ao responder a questão. As respostas encontradas no pré-teste foram as seguintes:

Tabela 2 - Local onde os respondentes mais utilizam o computador

\begin{tabular}{l|c}
\hline Respostas & Sujeitos \\
\hline No trabalho & 7 \\
\hline Em casa & 10 \\
\hline Em uma Lan House & 2 \\
\hline Casas de amigos/ amigos/ familiares & 0 \\
\hline Outros & 0 \\
\hline
\end{tabular}

Fonte: Elaborado pelas autoras

Esta pergunta leva a considerações sobre o local de trabalho e a utilização do computador pelos sujeitos participantes da pesquisa. Nota-se que a residência é o local em que os sujeitos mais operam esta ferramenta, deixando o ambiente escolar em segundo plano.

Figura 3 - Como os sujeitos consideram seu nível de conhecimento em informática

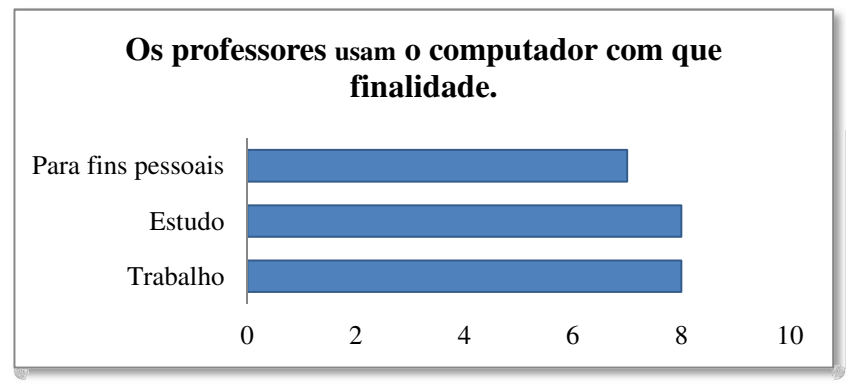

Fonte: Elaborado pelas autoras

$\mathrm{Na}$ pergunta seguinte, os respondentes expuseram como consideram seu nível de conhecimento de informática: $60 \%$ (sessenta por cento) declararam que seu conhecimento é básico. Esse índice pode levar a reflexões sobre a falta de habilidade dos docentes quanto ao uso do computador e, consequentemente, sua resistência em introduzir este recurso em sua prática.

Figura 3 - Os professores usam o computador com que finalidade

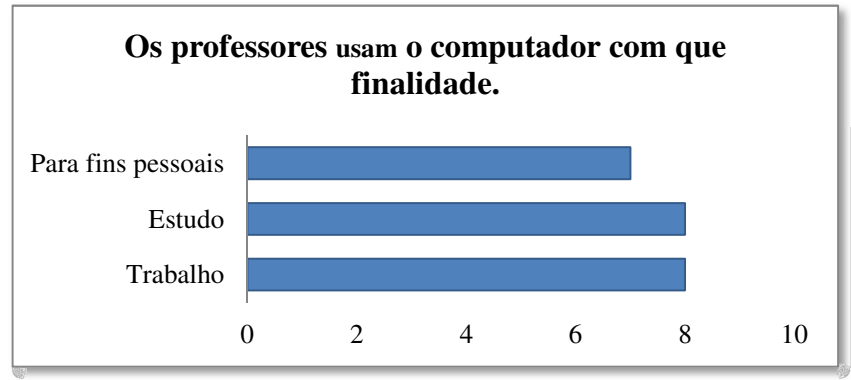

Fonte: Elaborado pelas autoras

Observa-se na figura 4, que os professores que utilizam o computador para fins diversos: trabalho, estudo e fins pessoais. Estas atividades equilibram-se o que demonstrando que realmente esta ferramenta esta associada à nova conjuntura social.

Figura 5 - Ambientes virtuais que os respondentes costumam acessar na internet

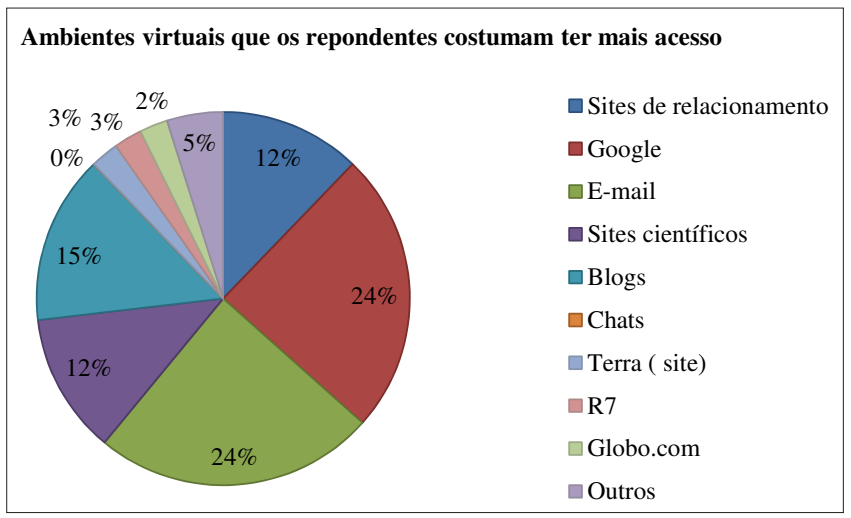

Fonte: Elaborado pelas autoras

É unânime a afirmativa dos participantes do pré-teste quanto à facilidade de acesso à internet, posteriormente os respondentes escolheram quais ambientes virtuais tem mais acesso. Este novo item foi ilustrado abaixo através da figura 6 . 
Figura 6 - Número de sujeitos que já visitaram um blog

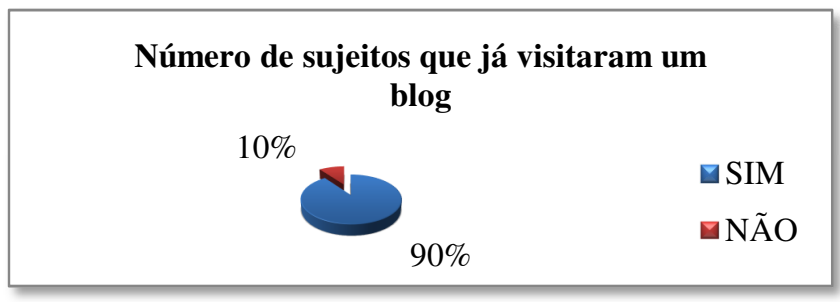

Fonte: Elaborado pelas autoras

Os blogs - objeto de estudo da pesquisa - estão em segundo lugar entre os mais visitados. Conforme se observa na figura $6,90 \%$ dos sujeitos já visitaram um blog, o que demonstra sua popularidade entre o corpo docente.

Dentre os conteúdos de blogs mais acessados, destacam-se aqueles voltados a conteúdos pedagógicos como mostra a figura 7. Este resultado nos conduz a indagações sobre as formas de aprendizagem também adotadas pelos docentes já que os blogs são ambientes onde podem interagir e compartilhar seus conhecimentos.

Há uma segunda hipótese que parece ser mais plausível do que a primeira, pois parte do princípio de que os blogs auxiliam na metodologia de ensino empregada pelo corpo docente ao sugerirem atividades e muitos deles têm sequências didáticas, projetos, atividades já prontas. Assim, os professores buscam neles materiais para a elaboração de seu planejamento diário. Porém, são imprescindíveis que saibam adequar as sugestões contidas nestes ambientes ao seu local de trabalho para que não ocorra a massificação e aprendizagem desconectada com a realidade em que os alunos estão inseridos.

Figura 7- Tipos de conteúdo dos blogs visitados pelos sujeitos

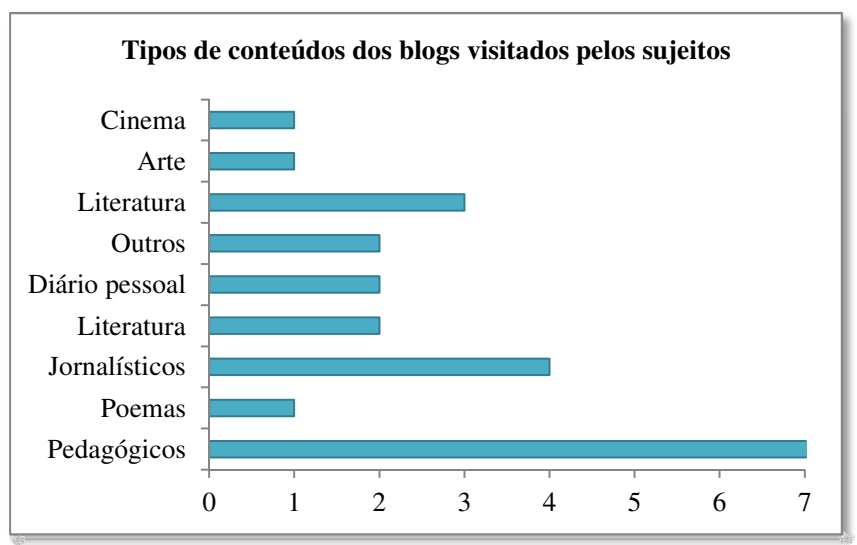

Fonte: Elaborado pelas autoras
Porém aos serem questionados se possuem um blog como ambiente virtual, foi revelado apenas um respondente com esta característica.

Figura 8 - Número de sujeitos que tem um blog pessoal

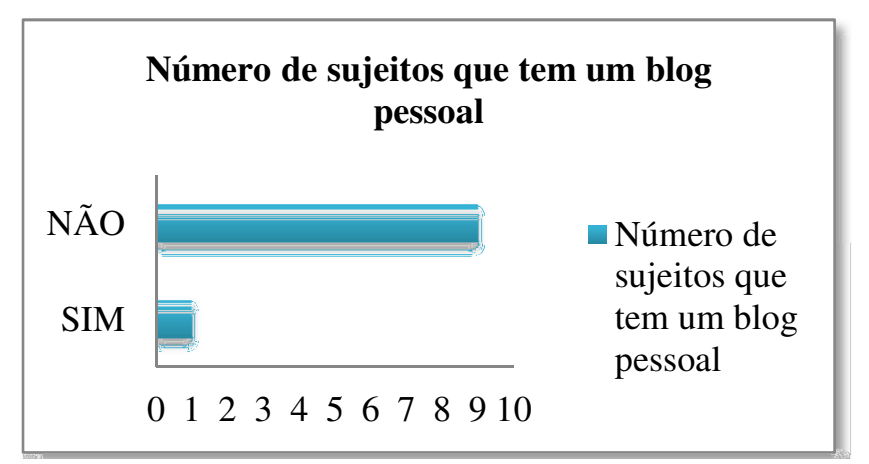

Fonte: Elaborado pelas autoras

A questão seguinte refere-se apenas aos sujeitos que tem blog, mas parece ter sido interpretada de forma errônea, devido aos resultados obtidos e tabulados na figura 8 , o que denota a necessidade de reformulação da pergunta. Em conversa informal, os sujeitos disseram que entenderam como eles aprenderam a visitar um blog - qualquer blog da internet - e não um blog pessoal.

Figura 9 - Como os sujeitos aprenderam a utilizar seu blog pessoal

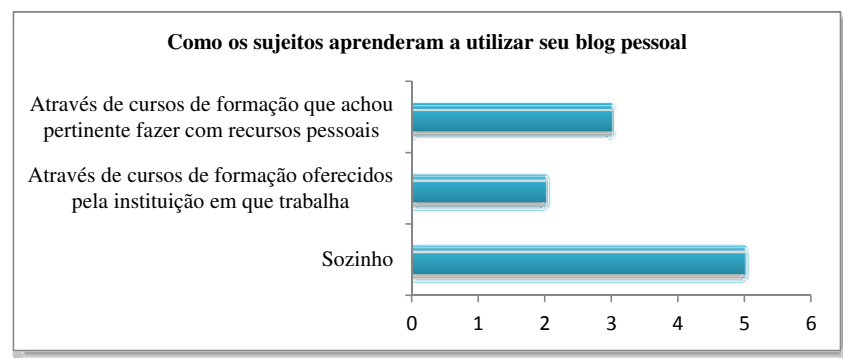

Fonte: Elaborado pelas autoras

Quanto ao blog da escola em que atuam, constatou-se que $23 \%$ não o conhecem, enquanto que $77 \%$ já tomaram conhecimento deste ambiente virtual como mostra a figura 10 . 
Figura 10 - Número de sujeitos que conhecem o blog da unidade escolar em que trabalham

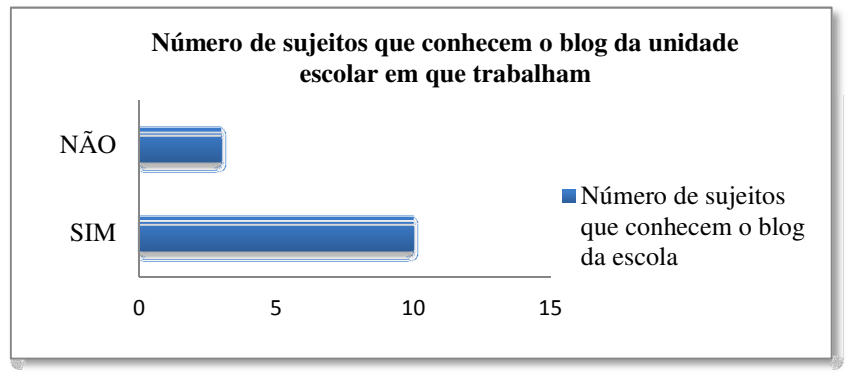

Fonte: Elaborado pelas autoras

Os sujeitos que já visitaram este ambiente representam $80 \%$ do total de sujeitos - como ilustrado na figura 11, o que mostra que esta pergunta também precisa ser reelaborada já que na questão anterior apenas $77 \%$ do total de respondentes alegam conhecer o blog da escola.

Figura 11 - Sujeitos que visitaram o blog da escola

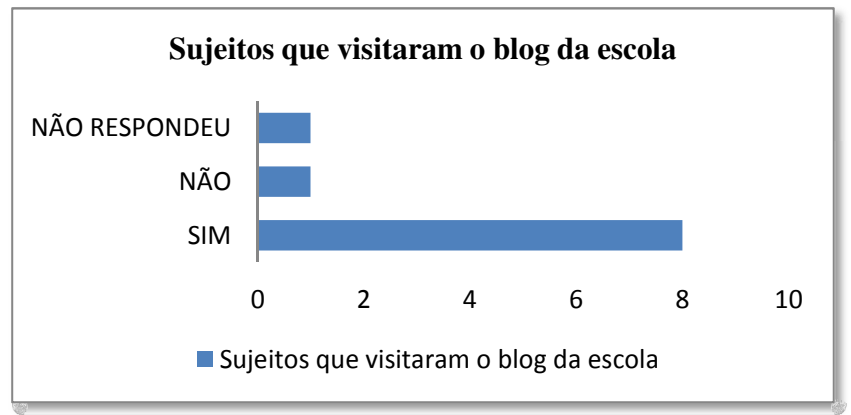

Fonte: Elaborado pelas autoras

Figura 12 - Como os sujeitos colaboram para a manutenção deste espaço

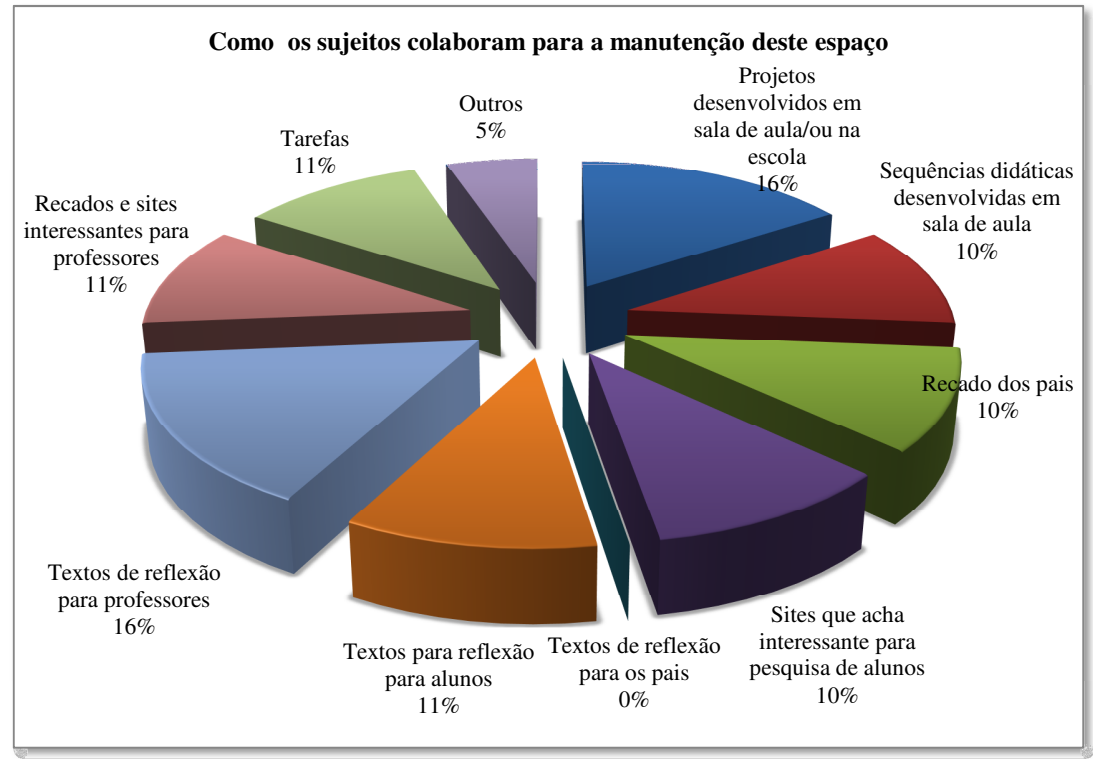

Fonte: Elaborado pelas autoras
Quanto à contribuição dos sujeitos neste ambiente, os resultados apontam que somente $30 \%$ dos sujeitos alimentaram o blog.

Enfim, os sujeitos revelaram quais suas contribuições efetivas para a manutenção do blog escolar, conforme mostra figura 12. Ainda, é possível perceber grande variedade de temas no ambiente - blog. $\mathrm{O}$ que pode evidenciar a utilização não planejada, resultando num emaranhado de conteúdos sem finalidade educacional. O ambiente torna-se um caderno de anotações onde tudo se torna interessante.

\section{Ajustes para um questionário}

O questionário como instrumento de pesquisa utilizado neste pré-teste mostrou-se relevante, visto que a parte inicial com questões referentes aos dados sóciodemográficos, embora com a necessidade alguns ajustes, forneceram dados importantes que permitiu caracterizar o perfil dos sujeitos.

Em relação à segunda parte (12 questões específicas), já na primeira pergunta que visa saber o local onde o sujeito tem mais acesso ao uso do computador, optaram por dar respostas múltiplas, diferente do esperado, demonstrando haver necessidade de uma nota explicativa, evidenciando a escolha por apenas uma resposta.

As perguntas de número 8 e 9 são extensões uma da outra e relacionam-se, particularmente, com o conhecimento que o indivíduo têm da interface blog: se eles têm um blog pessoal e como aprenderam a utilizá-lo. Na pergunta 8 (Você tem um blog pessoal?), apenas um respondente afirmou ter um blog. Porém na pergunta 9, que seria extensão da pergunta 8 , os sujeitos responderam como se possuíssem esse ambiente. Diante deste resultado, optou-se por uma nota explicativa na pergunta 9 (responda somente se você tiver um blog pessoal).

As demais perguntas demonstraram ser autoexplicativas, pois os sujeitos não solicitaram esclarecimentos em nenhum momento.

Quanto ao tempo de duração para completar o questionário, os professores e gestores levaram em média 20 a 25 minutos, tempo considerado suficiente. 
Após os ajustes no instrumento de coleta, infere-se que este permitirá coletar os dados e atingir os objetivos da pesquisa.

\section{Considerações finais}

Através deste levantamento preliminar, foi possível observar que o tema blog e educação estão em evidência na realidade das escolas. $\mathrm{O}$ instrumento de pesquisa, questionário fechado, mesmo necessitando de ajustes, demonstrou ser eficaz para responder aos objetivos da pesquisa, permitindo também, traçar o perfil dos sujeitos, sua relação com o blog escolar, destacando habilidades e dificuldades na mediação desta ferramenta no âmbito escolar.

Todos os dados além de nortearem as pesquisadoras nas adequações do instrumento de pesquisa, reiteraram a hipótese inicial de que há uma grande necessidade de aprofundamento teórico sobre o objeto de estudo: blog na educação.

\section{Referências}

ADELL, Jorge. Educação 2.0. In: BARBA, Carme; CAPELLA, Sebastiá (Org.). Computadores em sala de aula: métodos e usos. Porto Alegre: Penso 2010.

BEHRENS, Marilda Aparecida. Projetos de Aprendizagem colaborativa num paradigma emergente. In: MORAN, José Manuel. Novas tecnologias e mediação pedagógica. Campinas SP: Papirus, 2006.

BELLONI, Maria Luiza. O que é mídia- educação: polêmicas do nosso tempo. Campinas- SP: Autores Associados, 2005

FARIA, Elaine turk; GIRAFFA, Lúcia Maria Martins. Educação online: uma educação inovadora. In: AUDY, Jorge Luis Nicolas, MOROSINI, Marília Costa. Inovação, universidade e relação com a sociedade. Porto Alegre: EDIPUCRS, 2009.

GRAY, David E. Pesquisa no mundo real. Tradução: Roberto Cataldo Costa; revisão técnica: Dirceu da Silva. Porto Alegre: Penso, $20122^{\mathrm{a}}$ edição

GRINSPUN, M.P.S.Z. Educação Tecnológica. In: GRINSPUN, M.P.S.Z (Org.). Educação Tecnológica: desafios e perspectivas. São Paulo: Cortez, 2009.

HASSE, Simone Hedwig. A informática na educação mito ou realidade? In: LOMBARDI, José Claudinei (ORG). Pesquisa em educação: história, filosofia e temas transversais. Campinas - SP. Autores Associados Histedbr; Caçador SC: UNC, 2000 - 2 edição.
JOBIM, Daniela Ribeiro de Bulhões. Comunidades Virtuais de Aprendizagem. In: MERCADO, Luis Paulo Leopoldo (Org.). Experiências com Tecnologias da Informação e Comunicação na Educação. Maceió: EDUFAL, 2006.

KENSKI. Vani Moreira. Tecnologias e ensino presencial e a distância. Campinas- SP: Papirus, 2003.

Educação e tecnologias: o novo ritmo da informação. Campinas - SP. Papirus, 2012.

LOPES, Jorge. $\mathbf{O}$ fazer do trabalho científico em ciências sociais aplicadas. Recife: Ed. Universitária da UFPE, 2006

MALHOTRA, Naresh. Pesquisa de Marketing: uma orientação aplicada. $6^{\text {a }}$ Ed. São Paulo: Bookmam,2010.

OLIVERIA, Aristóteles da Silva. Inclusão digital. (In) MERCADO, L.P. L (Org.) Experiências com tecnologias de informação e comunicação na educação. Maceió: EDUFAL, 2006.

OLIVEIRA, Rosa Meire Carvalho. Aprendizagem mediada e avaliada por computador: inserção do blog como interface na educação. In: SANTOS, Edméa; SILVA, Marco. Avaliação da aprendizagem educação online. São Paulo: Loyola,2006

SORJ, Bernardo. brasil@povo.com: a luta contra a desigualdade na Sociedade da Informação. Rio de Janeiro: Jorge Zahar: Editora Brasília, Unesco,2003.

UNGLAUD, DeltonLehr. Metodologia para a geração y: como orientar a geração pós-milênio. In: UNGLAUB, Eliel (Org.). Desafios Metodológicos do ensino. Engenheiro Coelho, SP: Unaspress -Imprensa Universitária Adventista, 2012.

VALENTE, José Armando; MORAN, José Manuel; ARANTES, Valéria Amorin. Entre pontos e contrapontos: parte III. In: VALENTE, José Armando; MORAN, José Manuel; ARANTES, Valéria Amorin. Educação (Org.). A distância: pontos e contrapontos. São Paulo: Summus, 2011.

Recebido: 15-01-2015

Aceito: 11-06-2015 